\title{
A Study of the Correlation between the Concentration of Particulate Matter and Green Area Ratio Measured through a Portable Monitoring System: With Particular Focus on the Case of Dalseo-Gu, Daegu Metropolitan City
}

\author{
Kyungsu Son1*, Sanghun Baek1, Eungho Jung2, Daewuk Kim¹ \\ ${ }^{1}$ Research \& Development Center, STADT Co., Ltd., Daegu, Korea \\ ${ }^{2}$ Department of Global Environment, Keimyung University, Daegu, Korea \\ Email: *sks@stadt.co.kr
}

How to cite this paper: Son, K., Baek, S. Jung, E. and Kim, D. (2022) A Study of the Correlation between the Concentration of Particulate Matter and Green Area Ratio Measured through a Portable Monitoring System: With Particular Focus on the Case of Dalseo-Gu, Daegu Metropolitan City. Journal of Environmental Protection, 13, 84-96. https://doi.org/10.4236/jep.2022.131005

Received: December 15, 2021

Accepted: January 14, 2022

Published: January 17, 2022

Copyright ( 2022 by author(s) and Scientific Research Publishing Inc. This work is licensed under the Creative Commons Attribution International License (CC BY 4.0).

http://creativecommons.org/licenses/by/4.0/ (c) (i) Open Access

\begin{abstract}
This study analyzed the relationship between the measured concentration of particulate matter (PM) and green area, which is an important spatial factor affecting urban PM concentration and even more carbon neutral in cities. In order to investigate the effects of green area, the green area ratio (GAR) is used and correlated with particulate matter. As a result of analyzing the correlation between GAR and PM concentration using the measured PM data, it was found that there was a positive correlation between the two variables. Hence, the higher the GAR, the lower the PM concentration. It can be said that the introduction of spatial elements with high GAR scores, such as parks and forests in cities, is effective in reducing PM concentration. In this study, a portable PM monitoring system using a vehicle for PM measurement was also established and operated. As a result, it was found that a PM monitoring system using a light-scattering sensor is an effective PM measurement method that can be used at the local government level. It was also found that a follow-up study is needed in the future to identify the PM mitigation functions of urban green areas according to the detailed characteristics of green areas as well as various environmental factors. This study can be used in air quality improvement activities and efforts as reference data by policy decision makers and in the field of environmental planning associated with the removal of airborne particulate matter pollution in urban areas.
\end{abstract}

\section{Keywords}

Particulate Matter (PM), Correlation, Green Area Ratio (GAR), 
Monitoring System

\section{Introduction}

Particulate matter (PM) air pollution is recognized as a serious global environmental issue. A sharp rise in the concentration of PM originating from abroad or generated in South Korea not only harms the health of the nation's citizens but also leads to economic damage and losses. This raises the need to find measures to preemptively respond to PM issues by local governments along with efforts to solve problems at the national level.

In order to reduce PM, matter, it is important to understand the factors that contribute to the increase or decrease in PM concentration [1]. PM air pollution in cities is due to the generation and dispersion of PM generated within urban areas. PM is primarily generated by mechanical processes such as mechanical friction and fuel combustion. Other PM may be formed from the secondary reaction of gaseous air pollutants [2]. Various and complex environmental factors are involved in changes in generated PM. Among them, forests and green areas are the major factors that reduce PM concentration. As a major preceding study related to the reduction of PM concentration, a study analyzing the effect of reducing PM using green areas in downtown areas [3] and a study analyzing the correlation between meteorological factors and PM concentration [4] were conducted. However, there are few studies that measure the concentration of PM and analyze the effects of factors that reduce the concentration of PM based on the accumulated data.

Therefore, in this study, correlation analysis was performed in order to present the correlation between PM and GAR among various PM-related environmental factors and the change in PM concentration. To this end, usability was also reviewed with the operation of a PM monitoring system in real time in small areas. To this end, after examining the characteristics of PM and the PM reduction function of green areas through a theoretical review, the study area was selected and reviewed its utility through the operation of a real-time PM monitoring system. At this time, a measurement method suitable for monitoring PM in a small area also was selected.

\section{Theoretical Considerations}

\subsection{Characteristics of PM}

Particulate matter (PM) is made up of very small particles floating in the air and refers to dust that is invisible to the naked eye. In general, PM10 is defined as particulate matter that has a diameter of $10 \mu \mathrm{m}$ or smaller, and PM2.5 refers to particulate matter that is $2.5 \mu \mathrm{m}$ or less in diameter [5].

PM is classified as a Group 1 carcinogen by the World Health Organization (WHO), and is reportedly associated with adverse health effects. It can penetrate 
deeply into the human body via the respiratory tract, causing stroke, dementia, cancer, heart attack or lung disease. Also, it has reportedly adversely affected the growth and development of the fetus. Therefore, continuous inhalation exposure to PM adversely affects the human immune system, which is our body's energy source and defense against infections and disease, and is highly likely to lead to the development of various chronic physical conditions. Therefore, it can be said that the most dangerous consequences from particulate matter are adverse health effects. Even healthy people can experience pain and suffering from PM. Diseases from exposure to PM include rhinitis, pneumonia, acute atopic dermatitis, skin rashes, asthma including a dry cough, lung pain, tonsillitis, laryngitis, bronchiolitis and dry eye syndrome. PM exposure also worsens underlying diseases.

Fine particulate matter originating in China is estimated to cause $30 \%-50 \%$ of domestic air pollution, while domestically generated fine particulate matter causes 50\% - 70\% according to the government. In 2006, the National Aeronautics \& Space Administration (NASA) and Chinese environmental experts investigated the contribution of air pollutant emissions on annual basis for all regions in China. The results of the survey showed that three regions including Shandong Province (1,702,000 tons), Hebei Province (1,371,000 tons), and Jiangsu Province $(200,000$ tons) in the northeast region of China are the top three sources of air pollutant emissions. These provinces, which are close to Korea, are the most densely populated regions in China and are considered severe air pollution sources with high transportation emissions and industrial activities from industrial complexes. Accordingly, it is known that about 43\% of PM pollution comes from China. In fact, when the operation of aging thermal power plants in Korea was largely shut down in 2017, PM decreased by only $1.1 \%$, proving this. This suggests that issues related to PM are not only domestic problems that can be solved in Korea, but ones that must be resolved diplomatically with China.

\subsection{PM Mitigation and Functions of Green Areas}

There are various factors that influence the increase or decrease in PM concentration. When internal factors that influence PM concentration are considered as PM sources, various and complex factors such as meteorological conditions including precipitation and wind speed, structural elements of green spaces, vegetation index, population density, traffic volume, building distribution, and land use factors have a correlation with PM concentration.

Among them, a number of studies have been conducted on the functions of green areas related to PM mitigation. Some PM can be mitigated by trees and plants, as they capture and absorb PM through their surfaces such as leaves, and stomata (leaf and bark pores) [6]. The effectiveness of trees and plants in PM reduction and the amounts of PM reduction differ by type and time [7] [8], and were affected by various factors such as vegetation volume and distance from roads.

In addition, among various environmental factors related to PM emissions, 
land cover contains information on the characteristics of urban surface use, so it is suitable to understand the impacts of urban space on changes in PM concentration. Among related studies, Choi et al. investigated the effect of land cover on PM concentration by analyzing the relationship between the monthly PM concentration monitored by the urban air monitoring network in Seoul and the ratio of land cover by type around the measurement stations [1]. Hoek et al. suggested in a number of studies on PM2.5 prediction and regression models that the major predictor variables include land cover, the area of factories/roads, traffic volume and population [9]. Fan et al. found that the buildings and green areas within residential areas had the greatest effect on the increase or decrease in PM concentration [10]. Another study on the distribution and characterization of PM in urban and rural areas found that dust emissions from wheeled vehicles and roads in winter acted as a common factor in the increase of PM in both urban and rural areas (Miguel et al.) [11].

\section{Research Methodology}

\subsection{Overview}

In order to analyze the correlation between PM concentration and green area ratio, the measurement of PM concentration should be prioritized. To this end, a target site was selected, and a PM monitoring system was established and operated. Afterwards, the measured PM concentration at each sensor point was converted into a database, and correlation analysis between PM concentration and the green area ratio was performed (Figure 1).

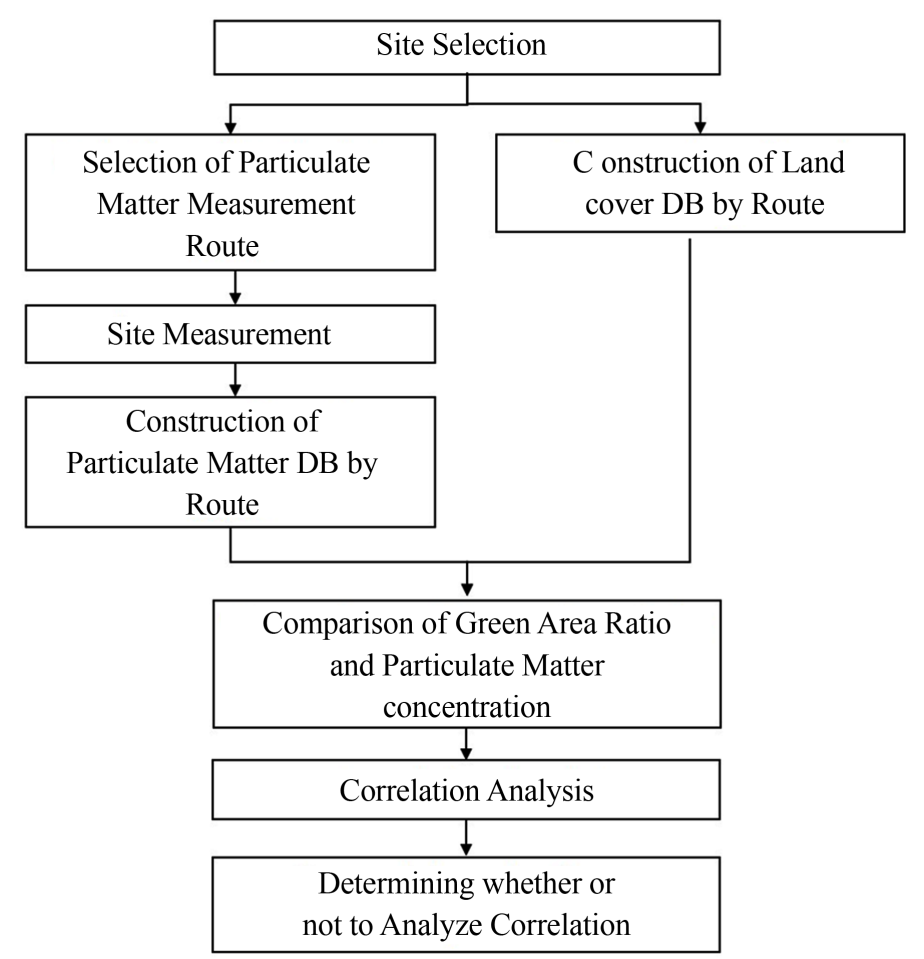

Figure 1. Research method. 


\subsection{Target Site Selection}

1) Monitoring Area Selection

There is a limit to acquiring micro-level information related to PM pollution and understanding the current status of PM pollution in the entire Daegu Metropolitan City area considering the research period and data. Therefore, in this study, PM monitoring was limited to Dalseo-gu, a district in Daegu Metropoli$\tan$ City.

Four large-scale industrial parks are located in the city center of Dalseo-gu. Consequently, PM air pollution and odor emissions from industrial activities are more serious than in other urban areas, and therefore, comprehensive measures are required. The roadside air quality monitoring station in Igok-dong, Dalseo-gu measured PM concentration, and the highest PM10 and PM2.5 concentrations were recorded as of 2019.

2) PM Measurement Route Selection

This study aimed to measure the status of PM pollution that citizens are felt and experienced in daily activities for the entire area of Dalseo-gu, Daegu Metropolitan City. A route of about $47 \mathrm{~km}$ was planned for the PM measurement route using a vehicle moving on the ground, comprehensively considering the air pollution monitoring networks in Dalseo-gu, vehicle mobility, land use, etc. (Figure 2).

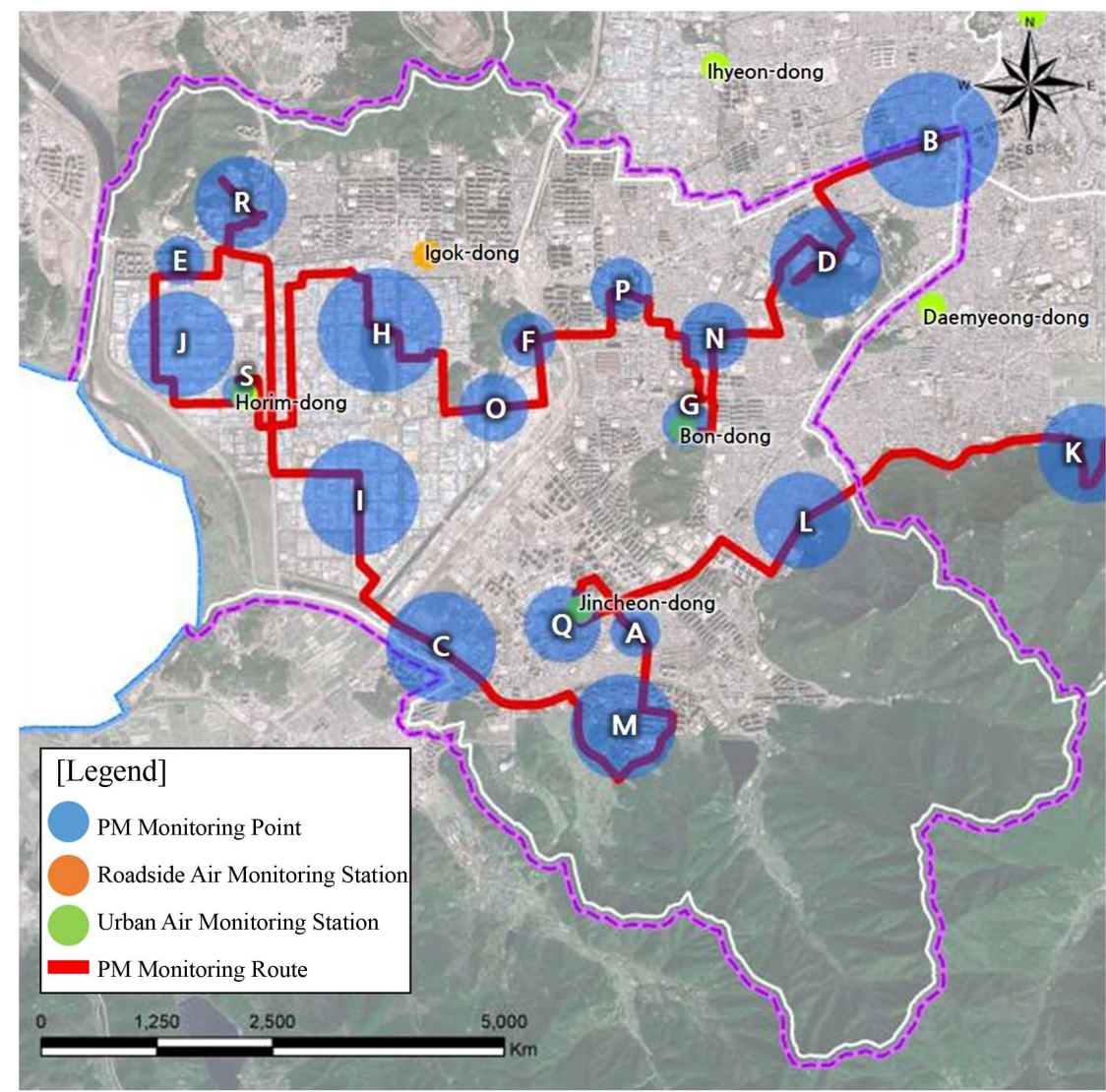

Figure 2. PM measurement route. 


\subsection{PM Measurement Method Selection}

The gravimetric method is the typical manual method for PM collection. Among automatic measurement methods, the beta gauge measurement method and the light scattering method are typical methods.

Currently, the Korean Ministry of Environment only recognizes the beta-ray absorption method (BAM) for PM measurement, but BAM instruments are expensive and there is a limit to real-time measurement with fixed-point sampling. Although the light scattering method that can be used for nearly simultaneous detection at all angles is also recommended in the United States and Europe, the Ministry of Environment has adopted the BAM because there may be an error in the measurement value. Therefore, it is necessary to prepare a measurement method for a mobile type rather than a fixed type. For the diversification of measurement technology, the introduction of the light scattering method as a measurement technology is also necessary.

As research data and a real-time measurement method are required for this study, the establishment and operation of a portable PM monitoring system for real-time PM measurement using a light scattering sensor was established and operated. In the light scattering method, when laser light is irradiated onto particles having the same physical properties, the intensity of the scattered light is proportional to the mass concentration of the particles. This is a method of measuring the intensity of the scattered light using this principle and obtaining the PM concentration from the value (Figure 3 [12]). The light scattering method has many advantages. Real-time measurement is possible, and the instrument is easy to carry. Multiple particles such as PM1.0, PM2.5, PM10 and TSP can be measured simultaneously using one instrument. On the other hand, there is a disadvantage that an error may occur in the process of obtaining the particle mass concentration through conversion after particle number concentration (PNC) measurements. Nevertheless, with its portability, many types of dynamic light scattering (DLS) instruments are on the market.

\subsection{Establishment and Operation of Monitoring System}

1) Establishment of monitoring system

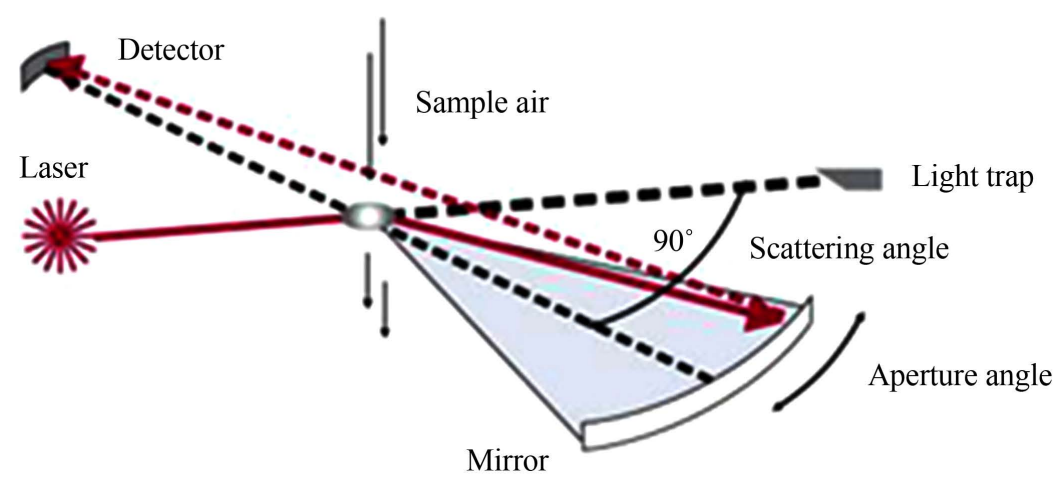

Figure 3. Principle of light scattering method. 
When monitoring PM pollution, the RF method was applied to establish a smooth communication environment between the monitoring equipment and the measurement instrument in order to grasp the measurement status in real time. The RF method is a broadband communication method using a frequency and has high stability because it is less affected by climate and environment. The data collected in real time, including location information, is streamed and expressed as spatial data. The measured PM data can be visualized and the PM concentration can be checked in real time. The related information can be stored in the monitoring server and shared (Figure 4).

2) Data collection system

The PM monitoring system is largely composed of data collection, data visualization, data analysis, and data storage. PM collection can be determined depending on the type of system built. In this study, real-time video data was acquired using a PM measurement instrument. A map-based real-time measurement and monitoring system was established using the operating equipment (laptop). The system was configured to enable simple data analysis and data inquiry by utilizing the measured data stored in the operating equipment in real time. The acquired data was saved in CSV and TXT formats for universal use. The data includes acquisition time, location information ( $\mathrm{X}, \mathrm{Y}$ and $\mathrm{Z}$ ), humidity, temperature, and PM concentration.

\section{Results}

\subsection{Results of PM Measurement through the Monitoring System}

To measure the PM concentration, a total of 19 PM measurements were carried out using a vehicle (from July to November 2020). In order to measure PM concentration when atmospheric stability is secured and not to be affected by moving vehicles during measurement, 10 measurements were carried out at night after midnight. Nine measurements were carried out during the day while moving

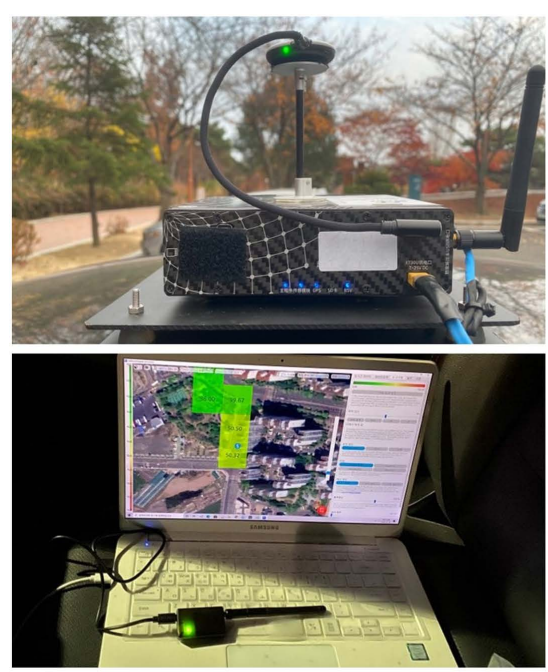

Real-time communication connection using RF method
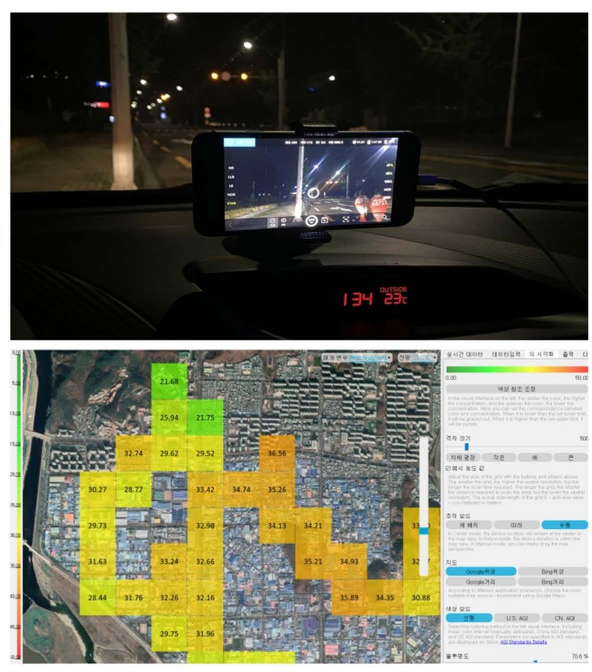

Real-time data display

Figure 4. Real-time PM monitoring system operation. 
so as not to be affected by the vehicle's moving speed and other moving vehicles as much as possible. Based on the planned measurement route, PM was measured while moving at a speed of $40 \mathrm{~km}$ per hour or less. According to the data from the roadside air quality monitoring station, the PM concentration on July 15, when it rained, was the lowest, while the PM concentration on November 17 was the highest.

In the case of PM data measured in this study, the average concentration of PM10 was $39.3 \mu \mathrm{g} / \mathrm{m}^{3}$ and PM2.5 was $27.2 \mu \mathrm{g} / \mathrm{m}^{3}$. The average PM concentration measured by the roadside air quality monitoring station (Igok-dong) in Dalseo-gu on the same day showed $35.6 \mu \mathrm{g} / \mathrm{m}^{3}$ for PM10 and $23.8 \mu \mathrm{g} / \mathrm{m}^{3}$ for PM2.5. The average PM concentration by measurement location was classified into daytime, nighttime, and daily averages as shown in the following table, and the current status of PM concentration was summarized (Table 1).

In order to easily understand the PM distribution based on the PM concentration data including location information collected in 1 second units, it was visualized by grids maps with a resolution of $500 \mathrm{~m} \times 500 \mathrm{~m}$. The PM distribution by measurement day is as follows (Figure 5).

Table 1. Current status of PM pollution by main location point.

\begin{tabular}{|c|c|c|c|c|c|c|c|c|c|c|}
\hline & \multirow[t]{2}{*}{ Type } & \multicolumn{3}{|c|}{$\begin{array}{l}\text { Daytime Avg. } \\
\qquad\left(\mu \mathrm{g} / \mathrm{m}^{3}\right)\end{array}$} & \multicolumn{3}{|c|}{$\begin{array}{l}\text { Nighttime Avg. } \\
\qquad\left(\mu \mathrm{g} / \mathrm{m}^{3}\right)\end{array}$} & \multicolumn{3}{|c|}{$\begin{array}{l}\text { Total Avg. } \\
\left(\mu \mathrm{g} / \mathrm{m}^{3}\right)\end{array}$} \\
\hline & & PM1.0 & PM2.5 & PM10 & PM1.0 & PM2.5 & PM10 & PM1.0 & PM2.5 & PM10 \\
\hline A & Commercial Area & 12.8 & 23.1 & 34.3 & 15.4 & 27.2 & 39.1 & 13.8 & 24.6 & 36.1 \\
\hline B & Wide Road & 16.6 & 30.4 & 43.1 & 18.8 & 34.2 & 49.9 & 17.6 & 32.2 & 46.3 \\
\hline $\mathrm{C}$ & Wide Road & 17.1 & 29.6 & 42.8 & 13.7 & 24.7 & 36.6 & 15.6 & 27.4 & 40.0 \\
\hline $\mathrm{D}$ & Park & 11.7 & 22.0 & 31.6 & 16.4 & 28.5 & 41.5 & 13.7 & 24.7 & 35.8 \\
\hline $\mathrm{E}$ & Park & 11.9 & 22.3 & 31.2 & 14.8 & 27.9 & 40.9 & 13.0 & 24.5 & 34.9 \\
\hline $\mathrm{F}$ & $\begin{array}{c}\text { Mixed Land } \\
\text { Use Area }\end{array}$ & 13.3 & 24.6 & 35.1 & 24.6 & 43.0 & 62.6 & 18.1 & 32.4 & 46.8 \\
\hline G & Residential Area & 12.2 & 22.4 & 32.3 & 25.1 & 42.2 & 59.8 & 17.1 & 29.9 & 42.8 \\
\hline $\mathrm{H}$ & Industrial Area & 16.5 & 29.9 & 42.1 & 22.9 & 40.4 & 58.1 & 19.2 & 34.3 & 48.7 \\
\hline I & Industrial Area & 15.5 & 27.7 & 40.9 & 16.4 & 28.8 & 41.8 & 15.8 & 28.2 & 41.3 \\
\hline $\mathrm{J}$ & Industrial Area & 12.9 & 23.6 & 33.3 & 16.5 & 30.0 & 42.8 & 14.4 & 26.2 & 37.3 \\
\hline K & Park & 10.1 & 18.7 & 28.4 & 8.3 & 15.5 & 23.0 & 9.4 & 17.4 & 26.1 \\
\hline $\mathrm{L}$ & Wide Road & 11.7 & 21.0 & 31.4 & 11.3 & 21.1 & 31.1 & 11.5 & 21.0 & 31.3 \\
\hline M & Residential Area & 11.4 & 20.8 & 30.9 & 10.5 & 19.2 & 27.6 & 11.1 & 20.2 & 29.6 \\
\hline $\mathrm{N}$ & Residential Area & 12.3 & 23.4 & 33.2 & 19.6 & 33.8 & 48.6 & 15.2 & 27.5 & 39.3 \\
\hline $\mathrm{O}$ & Wide Road & 18.3 & 31.5 & 45.5 & 18.1 & 33.5 & 49.5 & 18.2 & 32.3 & 47.2 \\
\hline $\mathrm{P}$ & Commercial Area & 14.9 & 27.9 & 40.0 & 25.0 & 43.1 & 62.3 & 19.0 & 34.1 & 49.0 \\
\hline Q & Residential Area & 13.2 & 24.5 & 36.9 & 17.3 & 31.1 & 44.4 & 14.6 & 26.7 & 39.5 \\
\hline $\mathrm{R}$ & School & 12.1 & 21.7 & 30.7 & 14.3 & 25.5 & 37.0 & 13.0 & 23.2 & 33.2 \\
\hline$S$ & Industrial Area & 13.5 & 24.5 & 34.8 & 19.0 & 34.6 & 49.6 & 16.0 & 29.1 & 41.5 \\
\hline
\end{tabular}



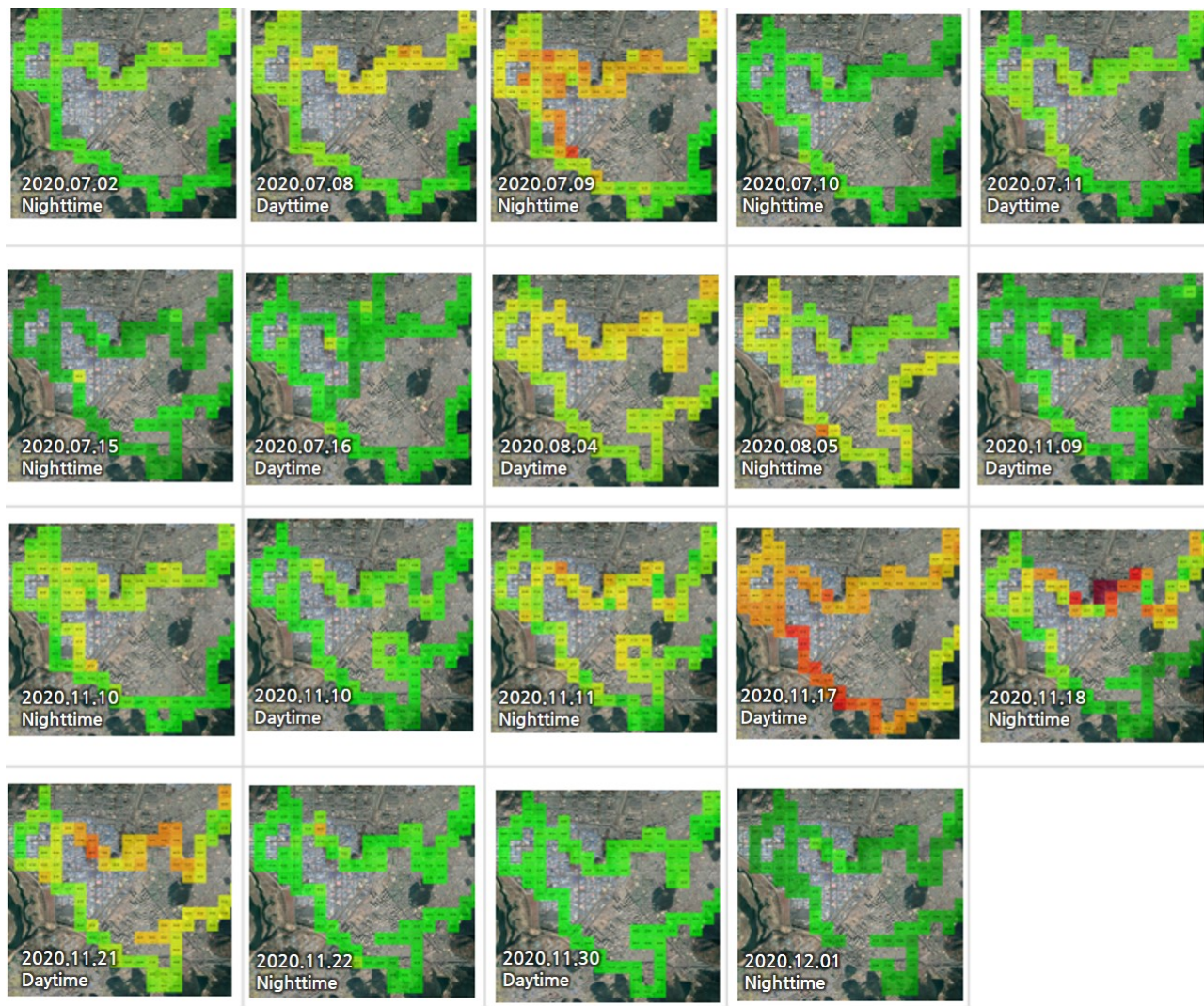

Figure 5. Visualization of PM measurements results.

\subsection{Analysis of Current Status of PM Pollution Based on Land Cover by Monitoring Route}

To prepare the PM distribution characteristics and improvement measures, understanding the current status of PM concentration by land cover was essential. For this purpose, land cover maps and data provided by the Ministry of Environment were used to understand how the PM concentration varies by land cover. Measured PM data using a vehicle was also examined. The statistical value of PM concentration according to land cover was calculated by matching the measured PM data to the land cover data. At this time, the land cover was largely classified into urban/built-up area, agricultural area, forest area, grassland area, wetland area, bare area, and water area (Figure 6).

As a result of analyzing the PM concentration by land cover, the industrial area showed the highest level, followed by the transportation area, residential area, and public facility area. On the other hand, the PM concentration was shown to be the lowest in the order of inland wetland area, coniferous forest area, cultivated area, and broadleaf forest area, followed by the mixed forest area with the lowest PM concentration. In other words, the PM concentration in forest areas such as the mixed forest area, coniferous forest area, and broadleaf forest area had a significantly lower PM concentration than that of other land cover classification areas. It means that forestry and tree-related facilities effectively reduce PM pollution (Table 2). 


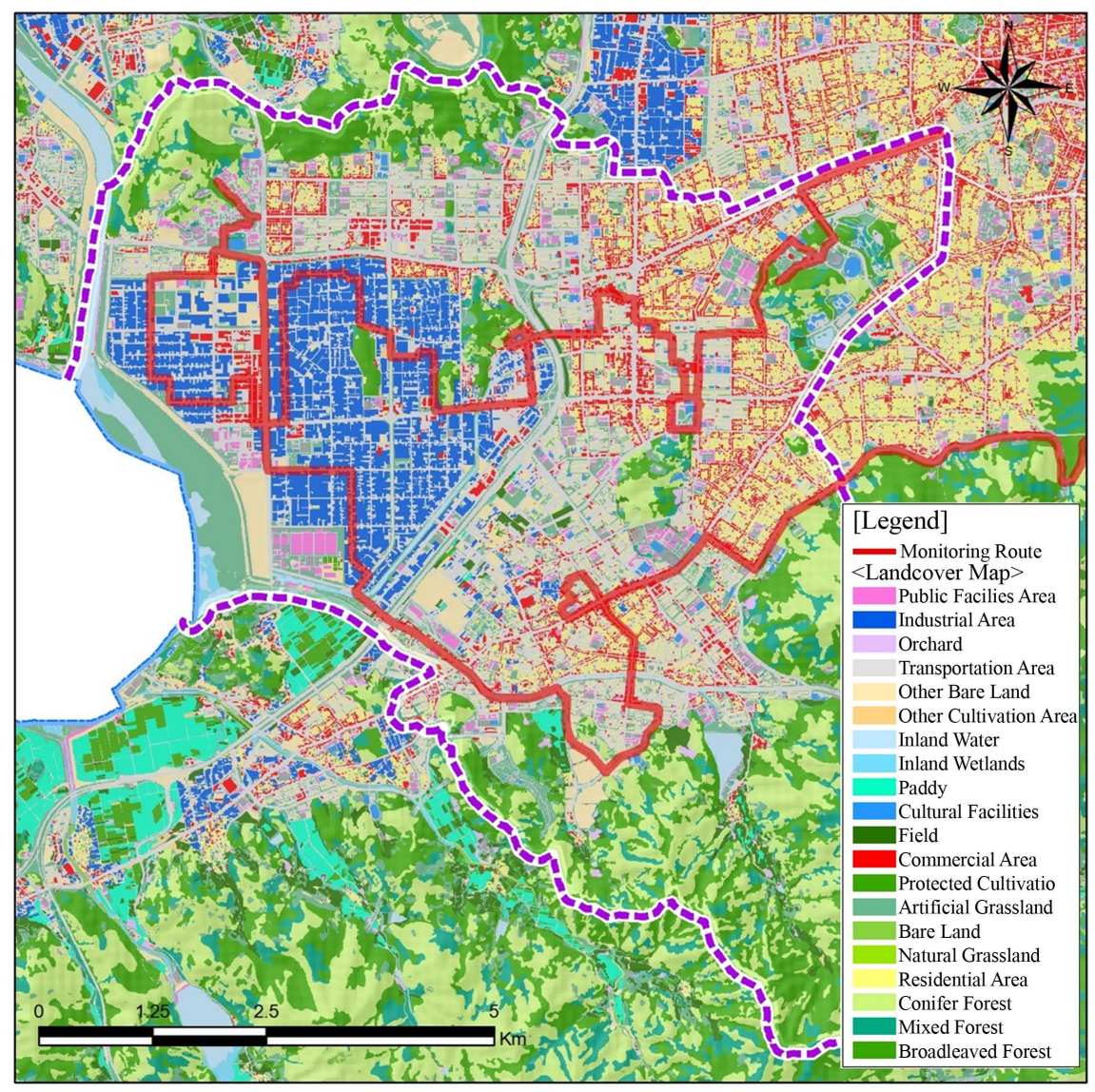

Figure 6. Current status of land cover in the target sites.

Table 2. Current status of PM concentration by land cover.

\begin{tabular}{cccc}
\hline Landcover & $\mathrm{PM} 1.0\left(\mu \mathrm{g} / \mathrm{m}^{3}\right)$ & $\mathrm{PM} 2.5\left(\mu \mathrm{g} / \mathrm{m}^{3}\right)$ & $\mathrm{PM} 10\left(\mu \mathrm{g} / \mathrm{m}^{3}\right)$ \\
\hline Mixed Forest & 9.0358 & 16.6733 & 23.7173 \\
Inland Wetlands & 10.6093 & 19.7928 & 28.3784 \\
Conifer Forest & 10.5776 & 19.7811 & 28.6932 \\
Cultivatio Area & 10.7009 & 20.1550 & 29.5854 \\
Broadleaved Forest & 11.0657 & 20.8787 & 30.3553 \\
Artificial Grassland & 13.3764 & 24.4029 & 34.7726 \\
Cultural Facilities & 13.6025 & 24.5004 & 35.3778 \\
Inland Water & 14.0059 & 24.9977 & 35.7625 \\
Other Bare Land & 14.8400 & 26.5969 & 38.2799 \\
Commercial Area & 14.9813 & 27.4096 & 39.3741 \\
Public Facilies Area & 15.6063 & 27.7621 & 39.9107 \\
Residential Area & 15.4800 & 28.1577 & 40.0701 \\
Transportation Area & 16.8418 & 31.3070 & 41.6179 \\
Industrial Area & 18.0113 & 33.0473 & 46.8087 \\
\hline
\end{tabular}




\subsection{Results of Correlation Analysis between PM Concentration and GAR}

According to the previous results in terms of land cover, it was found that the concentration of PM was relatively lower than that of areas without green-related land cover

In order to find a more detailed correlation between PM concentration and green-related land cover, a correlation analysis was performed on the concentration of PM and the green area ratio.

Correlation analysis was carried out to investigate the relationship between PM concentration and GAR. The GAR refers to the ratio of land cover related to green areas based on a radius of $500 \mathrm{~m}$ centered on the PM measurement point, that is, the ratio including mixed forest, inland wetlands, conifer forest, cultivation area, broadleaved forest, artificial grassland and inland water. The GAR was expressed in a grid of $500 \mathrm{~m} \times 500 \mathrm{~m}$, and correlation analysis was carried out by matching the PM concentration value to the measurement location (Figure 7).

As a result of the analysis, both PM10 $(-0.211)$ and PM2.5 (-0.192) showed a significant negative correlation with the GAR. Looking at the results of the correlation analysis for each time period, no correlation was found in the daytime time zone, but in the nighttime zone, PM10 showed a significant negative correlation of -0.431 while PM2.5 showed -0.434 . Therefore, the GAR is correlated
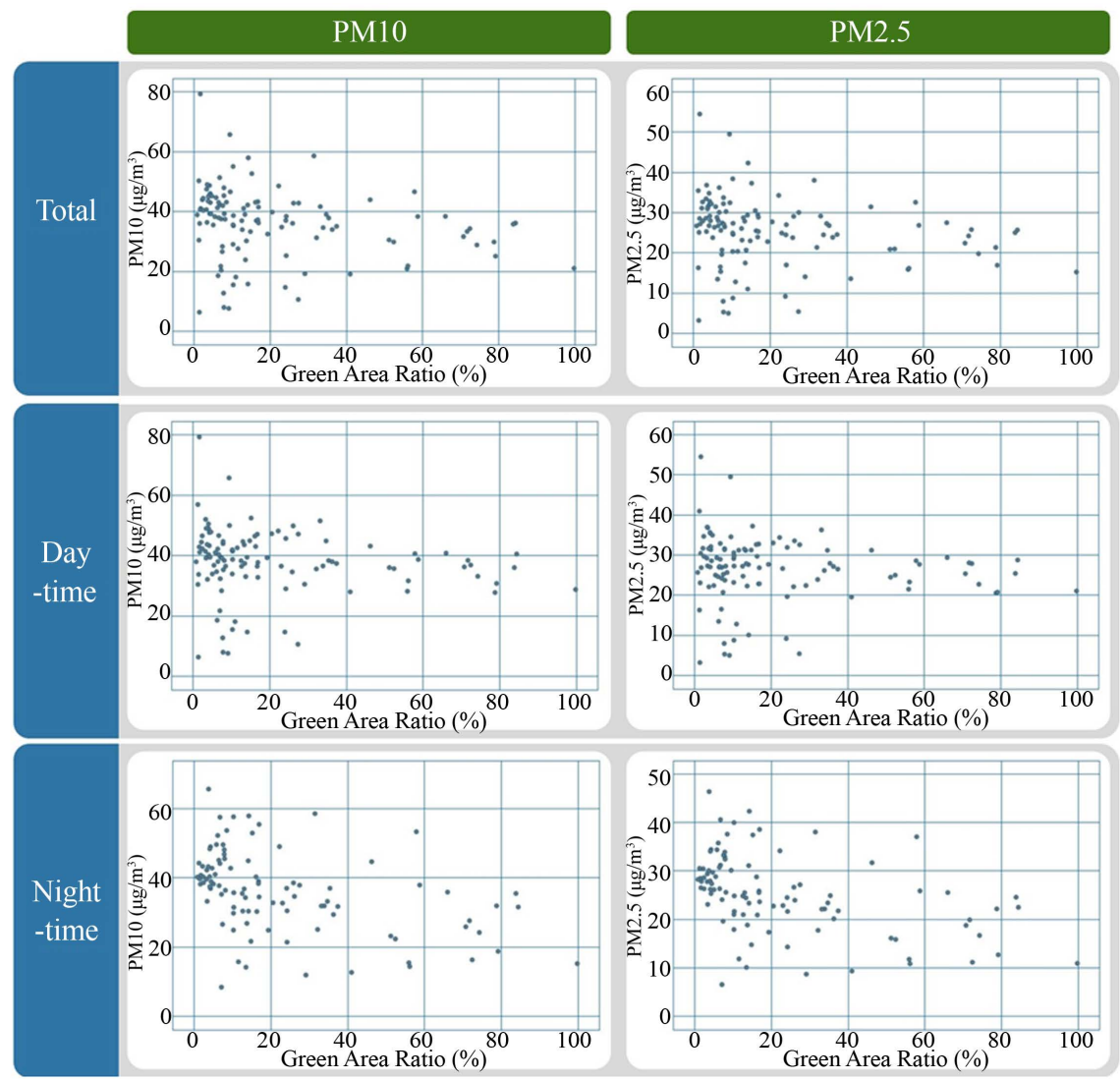

Figure 7. Scatter plot for PM concentration according to GAR. 
Table 3. Correlation between PM concentration and GAR.

\begin{tabular}{cccc}
\hline Type & Total & Daytime & Nighttime \\
\hline PM10 & $-0.211^{\star}$ & -0.128 & $-0.431^{\star \star}$ \\
PM2.5 & $-0.192^{\star}$ & -0.100 & $-0.434^{\star *}$ \\
\hline
\end{tabular}

${ }^{*} \mathrm{p}<0.05,{ }^{* *} \mathrm{p}<0.01$.

with the PM concentration especially at the nighttime. That is, as the GAR increases, the PM concentration decreases. In particular, such a trend was prominent in the nighttime zone when the atmosphere was stable. However, there was no correlation between the GAR and the PM concentration during the daytime, when there were many variables affecting the atmosphere (Table 3 ).

\section{Conclusions}

This study analyzed the relationship between the measured PM concentration and the GAR in order to investigate the effect on the green area ratio, a spatial factor affecting the urban PM concentration. At this time, a portable or mobile PM monitoring system using a vehicle was built and operated to measure PM pollution.

As a result of performing correlation analysis between the GAR and the PM concentration using the measured PM data, it was found that as the GAR increased, the PM concentration decreased. This means that the introduction of spatial elements with a high GAR score, such as parks and forests in the city, is effective in reducing PM concentration. However, no correlation was found during the daytime, which is presumed to be due to various variables (traffic volume, industrial activities, relatively high temperature, etc.).

In addition, in order to mitigate the PM concentration, it is important to understand the sources and distribution of PM. To effectively and practically respond to PM pollution, it is necessary to provide proper data on PM sources. To this end, it is necessary to lay the groundwork for a PM monitoring system directly linked to the daily activities of people from the macro-level in the city unit to the micro level. As a result of establishing and operating a mobile PM monitoring system and the measurement of PM concentration using a vehicle in this study, it is judged that PM pollution monitoring can be used effectively at the local government level using the method stated above.

This study suggests that the GAR in the city is a factor affecting the reduction of PM concentration. A follow-up study is needed to identify the PM mitigation functions according to the detailed characteristics of green areas as well as various environmental factors. The efforts of these improvement activities can be used as basic data for important policy decision making in the field of environmental planning related to particulate matter.

\section{Acknowledgements}

This research was supported by a grant (202104024041) from Research Program 
funded by Daegu Green Environment Center.

\section{Conflicts of Interest}

The authors declare no conflicts of interest regarding the publication of this paper.

\section{References}

[1] Choi, T.Y., Kang, D.I. and Cha, J.G. (2019) An Analysis of the Correlation between Seoul's Monthly Particulate Matter Concentrations and Surrounding Land Cover Categories. Journal of Environmental Impact Assessment, 28, 568-579.

[2] Kim, Y.P. (2017) Research and Policy Directions against Ambient Fine Particles. Korean Society for Atmospheric Environment, 33, 191-204. https://doi.org/10.5572/KOSAE.2017.33.3.191

[3] Xu, X.R. and Kim, J.O. (2017) Planting Design Strategies and Green Space Planning to Mitigate Respirable Particulate Matters: Case Studies in Beijing, China. Journal of Korean Institute of Landscape Architecture, 45, 40-49.

[4] Li, H., Guo, B., Han, M., Tian, M. and Zhang, J. (2015) Particulate Matters Pollution Characteristic and the Correlation between PM (PM2.5, PM10) and Meteorological Factors during the Summer in Shijiazhuang. Journal of Environmental Protection, 6, 457-463. https://doi.org/10.4236/jep.2015.65044

[5] Modaihsh, A., Mahjoub, M., Nadeem, M., Ghoneim, A. and Al-Barakah, F. (2016) The Air Quality, Characterization of Polycyclic Aromatic Hydrocarbon, Organic Carbon, and Diurnal Variation of Particulate Matter over Riyadh City. Journal of Environmental Protection, 7, 1198-1209. https://doi.org/10.4236/jep.2016.79107

[6] Nowak, D.J., McHale, P.J., Ibarra, M., Crane, D., Stevens, J. and Luley, C. (1998) Modeling the Effects of Urban Vegetation on Air Pollution. In: Gryning, S.E. and Chaumerliac, N., Eds., Air Pollution Modeling and Its Application XII, Springer, Boston, MA, 399-407. https://doi.org/10.1007/978-1-4757-9128-0_41

[7] Saebo, A., Popek, R., Nawrot, B., Hanslin, H.M., Gawronska, H. and Gawronski, S.W. (2012) Plant Species Differences in Particulate Matter Accumulation on Leaf Surfaces. Science of the Total Environment, 427-428, 347-354.

https://doi.org/10.1016/j.scitotenv.2012.03.084

[8] Cai, M., Xin, Z. and Yu, X. (2017) Spatio-Temporal Variations in PM Leaf Deposition: A Metaanalysis. Environmental Pollution, 231, 207-218. https://doi.org/10.1016/j.envpol.2017.07.105

[9] Hoek, G., Beelen, R., De Hoogh, K., Vienneau, D., Gulliver, J., Fischer, P. and Briggs, D. (2008) A Review of Land-Use Regression Models to Assess Spatial Variation of Outdoor Air Pollution. Atmospheric Environment, 42, 7561-7578. https://doi.org/10.1016/j.atmosenv.2008.05.057

[10] Fan, S., Li, X., Han, J., Cao, Y. and Dong, L. (2017) Field Assessment of the Impacts of Landscape Structure on Different-Sized Airborne Particles in Residential Areas of Beijing. Atmospheric Environment, 166, 192-203.

https://doi.org/10.1016/j.atmosenv.2017.07.026

[11] Canales-Rodríguez, M., Quintero-Núñez, M., Valdés-Salas, B. and Daessle-Heuser, W. (2015) Distribution and Characterization of PM10 in City and Valley of Mexicali, Baja California, Mexico. Journal of Environmental Protection, 6, 25-33. https://doi.org/10.4236/jep.2015.61004

[12] Min, S.G. (2014) Estimation of Dust Emission by Impact on Weathering Soil and Analysis of Dispersion Characteristic. Master's Thesis, Seoul University, Seoul. 